\title{
PRIMARY HEPATOCELLULAR CARCINOMA IN AN OTHERWISE HEALTHY LIVER
}

\author{
Major W. G. JOHNSTON, M.B., F.R.C.S.(Ed.), D.T.M.\&H., R.A.M.C. \\ Military Hospital, Tidworth
}

SUMMARY: Primary hepatocellular carcinoma is a comparatively rare disease in the European community. It is particularly rare in the absence of preceding liver disease.

A case of hepatoma occurring in the otherwise healthy liver of an English woman of 36 years of age is described.

\section{Introduction}

Primary hepatocellular carcinoma is a rare lesion in European races but in recent years several papers have been published suggesting that the incidence of the tumour is not as low as previously supposed. (Gall 1960, Manderson, Patrick and Peters 1965).

In the absence of preceding liver pathology primary hepatocellular carcinoma is exceedingly rare. No case reports were found in a search of the literature of the past decade.

A case of primary hepatocellular carcinoma in the otherwise healthy liver of an English woman is presented and some of the features discussed in the light of recently published research on this subject.

\section{Case history}

The patient, who was 36 years of age, had an eight day history of right-sided chest pain. The pain had been of rapid onset and centered posteriorly at the angle of the right scapula. It was sharp and pleuritic in type, being aggravated by deep breathing, coughing and laughing. Clinically her lung fields were clear and a chest X-ray was normal.

After six days the pain began to spread to the right subcostal region and became more severe. It was noticed that she looked more ill than she had done on previous visits, and that her sclerae had attained a muddy tinge. Examination revealed a now palpable liver edge 2 to 3 finger breadths below the costal margin.

When seen at the surgical clinic her pain had become much less severe and had settled in the right subcostal region. She was an aerophagist with a constant soft swelling in the epigastrium but otherwise there were no associated biliary and gastro-intestinal tract symptoms nor signs; her weight was steady.

\section{Previous history}

For many years the patient had been intolerant of fat but it was excluded from her diet from choice and not because it produced dyspeptic symptoms.

She professed to having feelings of panic when she felt hungry, but this was not associated with sweating, dizziness or fainting. Her stools were normal and there was no other clinical evidence of pancreatic insufficiency. 
The patient could only remember one episode of severe epigastric pain ten years previously. No medical advice was sought and the pain settled spontaneously after two days. At that time she was in the hotel trade and " drank beer and spirits fairly heavily". After her episode of pain she "cut it down" because she "thought she probably had an ulcer".

\section{Examination}

The patient was 175 centimetres tall, weighed 61.8 kilograms and had no stigmata of chronic illness. Temperature was $36.6^{\circ} \mathrm{C}$. Pulse $=70 / \mathrm{min}$ regular. B.P. $=110 / 70$ $\mathrm{mmHg}$. No abnormality was found in head, neck, respiratory system, cardiovascular system or skeleton.

The abdomen moved normally on respiration but there was a marked fullness in the epigastric region. She was tender in the right hypochondrium and in the epigastrium but there was no guarding or rebound tenderness.

Palpation showed a deep, fixed, rubbery mass 15 centimetres in diameter, moving only slightly with respiration. The liver edge could not be felt and the kidneys and spleen were neither palpably enlarged nor tender. No pelvic abnormality was detected.

\section{Investigations}

$X$-rays. Chest showed normal lung fields with equally raised diaphragm but with normal diaphragmatic movement. Abdomen showed there was suggestion of displacement of the stomach to the right and enlargement of the liver shadow.

Haemogram. Findings were-haemoglobin-12 g/100 ml. E.S.R.-37 mm in 1 hour. W.B.C. $-7,000 \mathrm{~mm}^{3}$ with normal differential.

Blood chemistry. Showed total bilirubin $-0.7 \mathrm{mg} / 100 \mathrm{ml}$. Serum alkaline phosphatase-27 King-Armstrong units/100 ml. SGOT-10 Karmen units/100 ml. SGPT -32 Karmen units/100 ml. Blood sugar (mid morning) - $128 \mathrm{mg} / 100 \mathrm{ml}$. Serum amylase - 100 Somogyi units $/ 100 \mathrm{ml}$.

Cholecystogram. Showed normal functioning gall bladder.

Barium meal and follow-through (Figs. 1 and 2). The oesophagus appeared normal. The stomach was displaced to the left and posteriorly, being compressed but apparently not invaded by a mass which was thought to be a much enlarged liver. The meal passed normally through the intestine. The colon showed displacement downwards and to the left.

Three weeks later the mass was more easily defined and the ESR had risen to $55 \mathrm{~mm}$ in 1 hour.

\section{Laparotomy}

The abdomen was opened through an upper midline incision. The liver looked normal but lying below it was a spherical mass, $15 \mathrm{cms}$ in diameter, brown in colour, of firm consistency and with engorged surface vessels. It was completely free except posteriorly, where it was found that the tumour was arising from the caudate lobe in the region of the inferior vena cava. The other organs in the region were normal.

During a very difficult dissection from pericaval tissues, haemorrhage from the hepatic portion of the vena cava became uncontrollable and the patient died in spite of massive transfusion. 


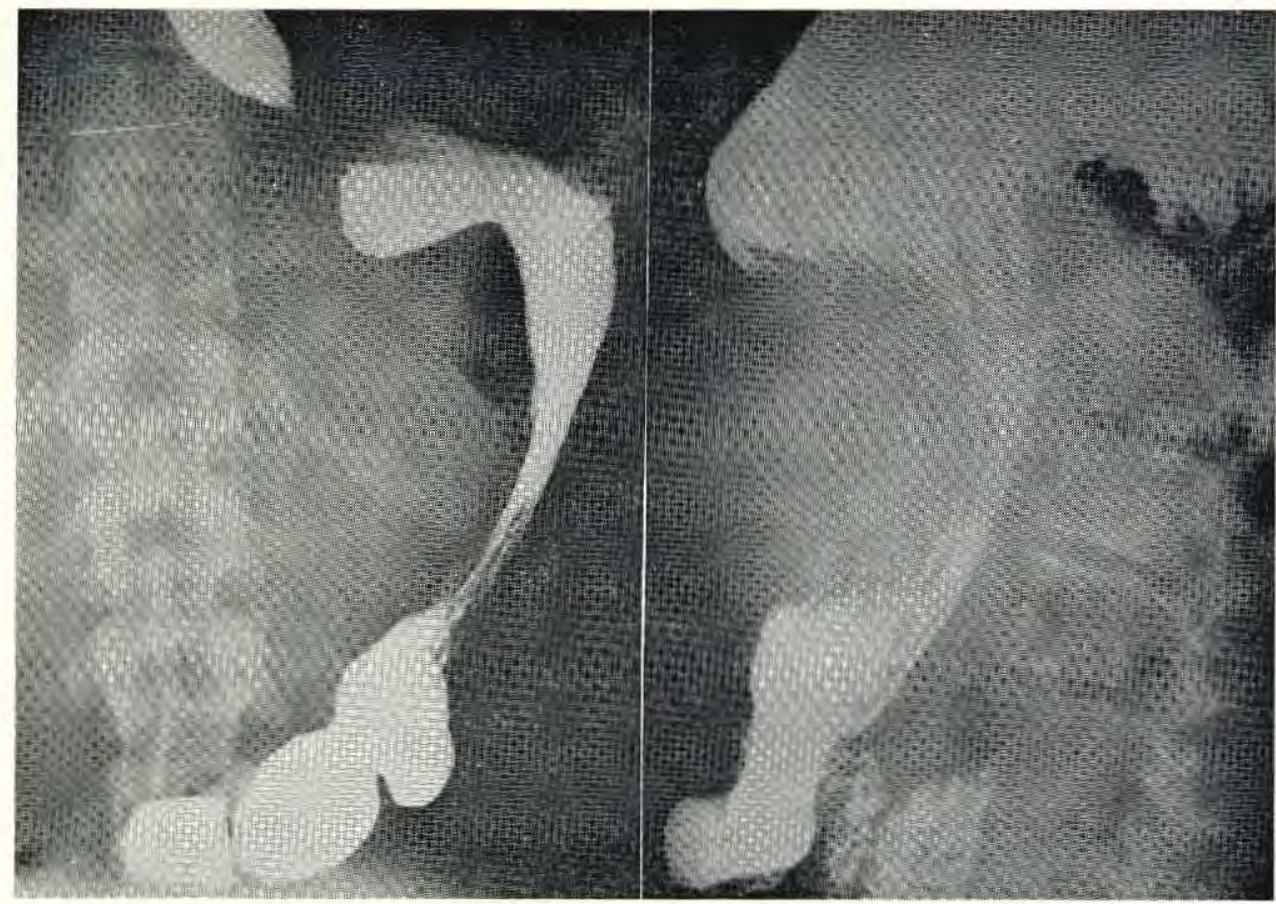

Fig. 1. Barium meal showing the lateral displacement of the stomach.

Fig. 2. A lateral view of the stomach during barium meal which shows apparent posterior displacement of the stomach.

\section{Post-mortem examination}

The liver in the region of the resection was extensively infiltrated by highly cellular tumour composed of large eosinophilic cells with central vesicular nuclei. Pleomorphism and mitotic activity were present. Adjacent to the tumour mass the cells showed advanced fatty change but otherwise the liver showed no pathological changes. The malignant tumour remaining in, and extensively infiltrating the right lobe of the liver was classified as a hepatocellular carcinoma.

\section{Pathology of the resected mass}

The mass measured $15 \mathrm{~cm}$ in diameter and weighed $1160 \mathrm{~g}$. Histological sections (Fig. 3) showed that the normal hepatic architecture was completely destroyed, there being well marked fibrous bands surrounding cellular areas. The tissue was of considerable cellularity with areas of necrosis and haemorrhage. Many of the cells showed the presence of bile. The cytoplasm of the cells was eosinophilic, and some of the cells were vacuolated. The cells were of hepatic type and neoplastic. The tumour was invading blood vessels. The diagnosis of primary hepatocellular carcinoma was confirmed.

\section{Discussion}

In a study of primary carcinoma of the liver Berman (1951) showed that it was rare to find this lesion in the population of Europe and North America. In Europeans 


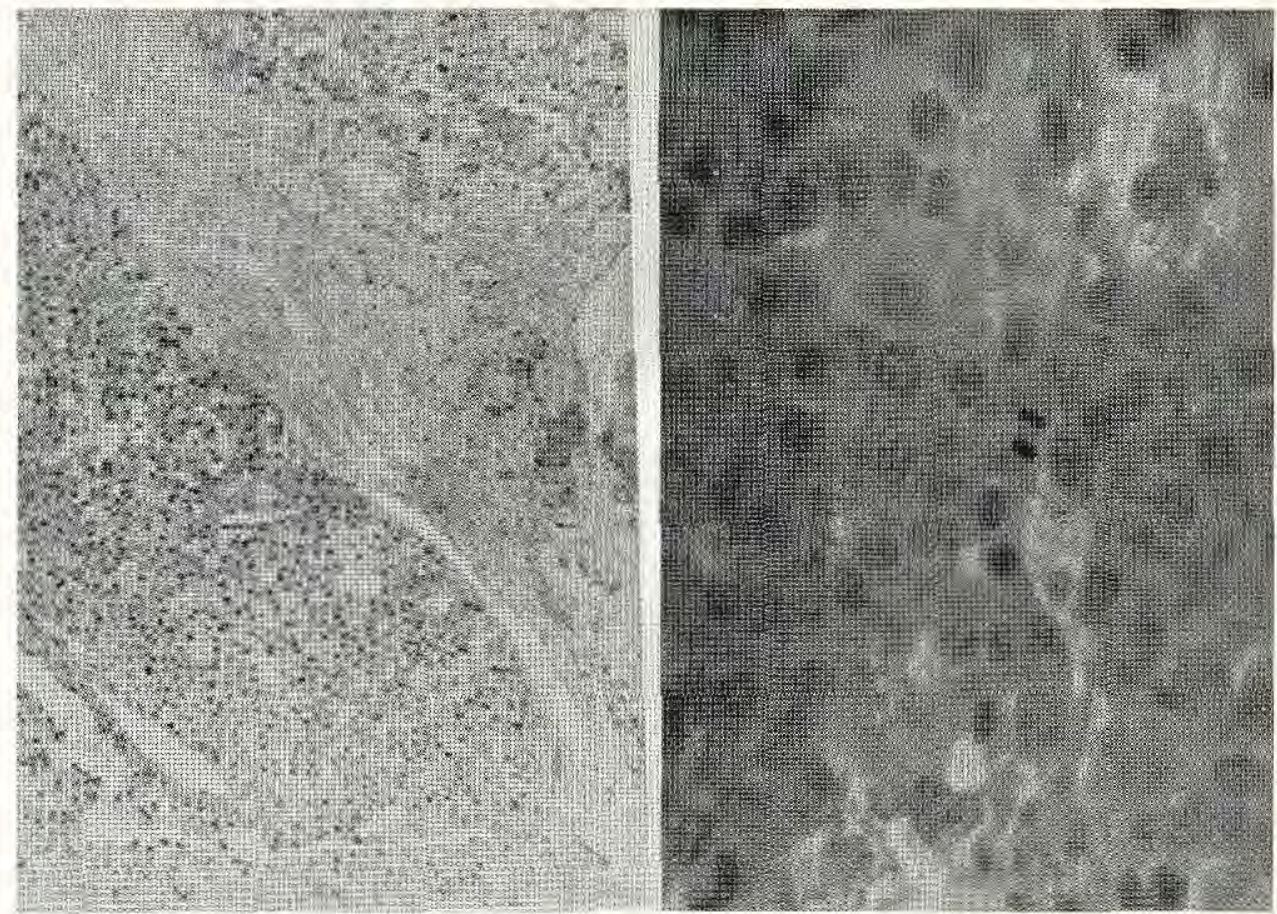

Fig. 3 Photomicrograph of the sections of the tumour demonstrating the well marked fibrous bands surrounding clumps of cells, some showing the presence of bile. Various stages of mitosis are present in the section.

only 1.2 per cent of cases of primary carcinoma of all organs were of liver origin: in Americans 2.5 per cent; in the Chinese 33.0 per cent; and in the Bantu tribes of S.E. Africa 50.9 per cent of primary carcinomas were of liver origin. He repeats these observations in a later review of the subject (Berman 1958), and others have confirmed his findings (Nelson, Elizalde and How 1966, Doll, Payne and Waterhouse 1966). Doll and his co-editors express their results as the incidence per 100,000 of the population. Rates of over 5 per 100,000 occur in Angola, South Africa, Nigeria, Uganda and Singapore. Between 5 and 3.1 per 100,000 are afflicted in Japan and Denmark but America, Europe and Australia are included amongst those areas with an incidence of less than 3.0 per 100,000 of the population. Anderson (1968) regards hepatoma as a sizeable medical problem in Scotland, quoting the death rate from this carcinoma as being 1.43 per 100,000 of the population.

Berman (1958) in his review also stated that it is becoming increasingly apparent that pre-existing liver damage is closely associated with the malignant process; the relationship with cirrhosis has been very fully documented. However, it is rare in cases of nutritional cirrhosis, and is found mainly in the post-necrotic and post-hepatitic livers (Gall 1960). Gall goes as far as to say that hepatocellular carcinoma occurs no more frequently in fatty livers of nutritional cirrhosis than it does in normal livers but Lee (1966) shows the incidence of hepatoma in the alcoholic to be in the order of 30 per cent. The high alcohol intake while "in the trade " is the only significant fact in the history of the case presented. 
Other recently reported features of hepatoma were absent from this case. Hypoglycaemia, although not confirmed by the blood sugar estimations, could have been presumed from the story of panic when hungry had there been some other confirmatory symptom. Anderson, Webster and Wypkema (1967) and McFadzean and Young (1969) found that 27 per cent of 142 patients with liver cell carcinoma showed varying degrees of hypoglycaemia. Brownstein and Ballard (1966), in a retrospective study of 213 cases of hepatoma found 9.4 per cent to have haemoglobin levels of over $16 \mathrm{~g} / 100 \mathrm{ml}$ and 2.8 per cent to have true erythrocytosis-a haemoglobin level of $18 \mathrm{~g} / 100 \mathrm{ml}$ and a haematocrit value of 55 per cent. There was no evidence of any such abnormality in this case, nor was there of eosinophilia which was found in a case by Rarke (1965).

From the position and form of the tumour in this patient it is most likely that it arose from the region of the caudate lobe and, until late, its growth was mainly extrahepatic, the spread into the right and left lobes occuring more slowly. In retrospect one cannot visualise how surgery could have successfully ablated this lesion; perhaps earlier diagnosis would have made perfusion with cytotoxics feasible. With the evidence that hepatoma is increasing in incidence, and that this increase is more than can be accounted for by the increase in incidence of hepatic cirrhosis (Manderson, Patrick and Peters 1965, Gall 1960), there should now be an increasing awareness of the possibility of its existence in cases of unexplained upper abdominal pain.

In a deep seated lesion such as this the early diagnosis can only be made on clinical suspicion supported by specialist investigations such as portosplenic venography, selective coeliac arteriography and radioisotopic liver scanning. The only simple investigation, apart from routine blood counts is the identification of foetal protein in adult serum. The presence of alpha-1-foetoglobulin has been proved in over 70 per cent of cases of primary hepatocellular carcinoma in the Bantu population (Purves, MacNab and Bersohn 1968); this figure is considerably less (27 per cent) in Europeans (Foli, Sherlock and Adinolfi 1969). Routine screening of susceptible patients using this relatively simple investigation, in spite of the low percentage of positive results in Europe, may be a useful aid toward earlier diagnosis.

\section{REFERENCES}

Anderson, I. F., Webster, A. L. and WypkemA, W. (1967). S. Afr. med. J. 41, 505. ANDERSON, J. M. (1968). Brit. med. J. iii, 554.

Berman, C. (1951). Primary Carcinoma of the Liver. H. K. Lewis \& Co. Ltd. London.

Berman, C. (1958). Advanc. Cancer Res. 5, 55.

Brownstein, M. H. and Ballard, H. S. (1966). Amer. J. Med. 40, 204.

Doll, R., Payne, P. and Waterhouse, J. (Eds). (1966). Cancer Incidence in Five Continents: A Technical Report. Heidelberg. International Union against Cancer: Springer-Verlag.

Foli, A. K., SHerlock, S. and Adinolfi, M. (1969). Lancet ii, 126\%:

Gall, E. A. (1960). Arch. Path. 70, 226.

LEE, F. I. (1966). Gut 7, 77.

McFADZEAN, A. and Young, J. (1969). Amer. J. Med. 47, 220.

Manderson, W. G., Patrick, R. S. and Peters, E. E. (1965). Scot. med. J. 10, 60.

Nelson, R. S., Elizalde, R.de. and How, C. D. (1966). Cancer 19, 533.

Purves, L. R., MacNAB, M. and Bersohn, I. (1968). S. Afr. med. J. 42, 1138.

RARKE, E. J. (1965). Amer. J. dig. Dis. 10, 548. 